\title{
Acid Catalysis with Alkane/Water Microdroplets in Ionic Liquids
}

\author{
Rossella Greco, Vicent Lloret, Miguel Ángel Rivero-Crespo, Andreas Hirsch, Antonio Doménech-Carbó, \\ Gonzalo Abellán,* and Antonio Leyva-Pérez*
}

Cite This: JACS Au 2021, 1, 786-794

Read Online

\section{ACCESS I \\ |lll Metrics \& More \\ Article Recommendations \\ Supporting Information}

ABSTRACT: Ionic liquids are composed of an organic cation and a highly delocalized perfluorinated anion, which remain tight to each other and neutral across the extended liquid framework. Here we show that $n$-alkanes in millimolar amounts enable a sufficient ion charge separation to release the innate acidity of the ionic liquid and catalyze the industrially relevant alkylation of phenol, after generating homogeneous, self-stabilized, and surfactant-free microdroplets $(1-5 \mu \mathrm{m})$. This extremely mild and simple protocol circumvents any external additive or potential ionic liquid degradation and can be extended to water, which spontaneously generates microdroplets $(\mathrm{ca} .3 \mu \mathrm{m})$ and catalyzes Brönsted rather than Lewis acid reactions. These results open new avenues not only in the use of ionic liquids as acid catalysts/solvents but also in the preparation of surfactant-free, well-defined ionic liquid microemulsions.

KEYWORDS: acid catalysis, ionic liquids, alkane microemulsions, water microdroplets, Friedel-Crafts reaction

\section{INTRODUCTION}

The extended framework of a typical ionic liquid (IL) neutralizes the innate ion charge separation between the cation, typically ammonium of general formula $\mathrm{R}_{4} \mathrm{~N}^{+}$, and the anion, typically a highly delocalized perfluorinated counteranion $\mathrm{XF}_{n}^{-}$[i.e., $\mathrm{BF}_{4}^{-}, \mathrm{PF}_{6}^{-}$, or $\mathrm{TFSI}^{-}$(bis(trifluoromethanesulfonyl)imide)], thus keeping the material neutral and without acidity. ${ }^{1-3}$ In stark contrast, the corresponding perfluorinated Brönsted acids and also the metal salts prepared thereof by halide metathesis, with general formula $\mathrm{MXF}_{n}$, show some of the higher acidity values recorded so far, active as superacid catalysts $\left(\mathrm{pH}<\mathrm{H}_{2} \mathrm{SO}_{4}\right)$ in organic reactions. ${ }^{4-7}$ In order to use the IL as an acid catalyst and a solvent, additional chemical modifications if not the partial decomposition of the IL have been reported, such as the generation of protons by partial hydrolysis, ${ }^{8-10}$ the addition of metal nanoparticles or external acids, ${ }^{11-15}$ and the incorporation of sulfonic, carboxylic, and metal anion functions into the IL chemical structure, which have been named Brönsted (BAILs) and Lewis acidic ionic liquids (LAILs), respectively. ${ }^{16}$ However, all these strategies require the permanent modification of the original IL structure, increasing significantly the costs for the acid function synthesis and just overlooking the innate acidity of ILs.

It is well-known that the polarity of ion pairs is enhanced in the presence of very apolar molecules, which is the basis of ionpairing catalysis. ${ }^{17-20}$ Thus, it may very well occur that tiny amounts of very apolar molecules will significantly disturb the
IL structure, to separate the ionic charges and enable the isolated ammonium cation to act as a Lewis acid. ${ }^{21,22}$

Figure 1 shows that, although conventional ILs do not dissolve simple alkanes even at very low amounts, their

\begin{tabular}{|c|c|c|c|}
\hline $\begin{array}{c}\mathbf{M}^{\oplus}--^{\ominus} \mathbf{X F}_{\mathbf{n}} \\
\text { Loosely bond in solution } \\
\text { Superacid } \\
\mathbf{M}=\mathrm{H}, \text { carbonium, metal,... }\end{array}$ & $\begin{array}{c}\mathbf{R}_{\mathbf{4}} \mathbf{N}^{\oplus} \Theta \mathbf{X F}_{\mathbf{n}} \\
\text { Tightly bond in the IL network } \\
\text { Neutral } \\
\mathbf{R}=\text { Alkyl, aryl }\end{array}$ & $\begin{array}{c}\begin{array}{c}+n \text {-alkane } \\
\text { or water } \\
(<1.5 \text { vol\%) }\end{array} \\
\stackrel{\longrightarrow}{\longrightarrow} \\
\text { (This work })\end{array}$ & $\begin{array}{c}\mathbf{R}_{\mathbf{4}} \mathbf{N}^{\oplus}--\mathbf{X F}_{\mathbf{n}} \\
\text { Charge separation } \\
\text { Acid } \\
\mathrm{R}=\text { Alkyl, aryl }\end{array}$ \\
\hline
\end{tabular}

Figure 1. Transformation of a neutral into an acid ionic liquid (IL) by polarization with small amounts of $n$-alkanes. $\mathrm{X}=\mathrm{P}, \mathrm{B}, \mathrm{N}\left(\mathrm{SO}_{2} \mathrm{C}\right)_{2} ; n=$ $4-6$.

interaction is governed by subtle interfacial forces, strongly dependent on the alkane length, that can lead to ion par separation. ${ }^{23,24}$ If so, the IL could be employed as a catalyst and a solvent without any significant alteration of the chemical structure, after just adding a very simple, cheap, and unreactive substance. $^{25,26}$

Alkane/IL mixtures tend to separate in a two-phase system unless a surfactant is added to generate microemulsions. ${ }^{27-31}$

Received: March 8, 2021

Published: May 12, 2021 


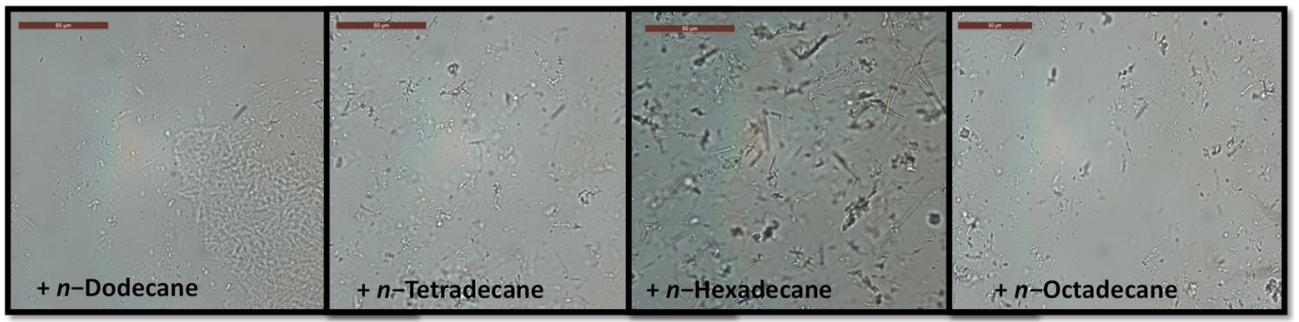

Figure 2. Optical microphotographs of $[\mathrm{bmim}]\left[\mathrm{PF}_{6}\right]$ in the presence of different $n$-alkanes $\left(0.5\right.$ vol \%) after heating at $150{ }^{\circ} \mathrm{C}$. The scale bar indicates $50 \mu \mathrm{m}$.
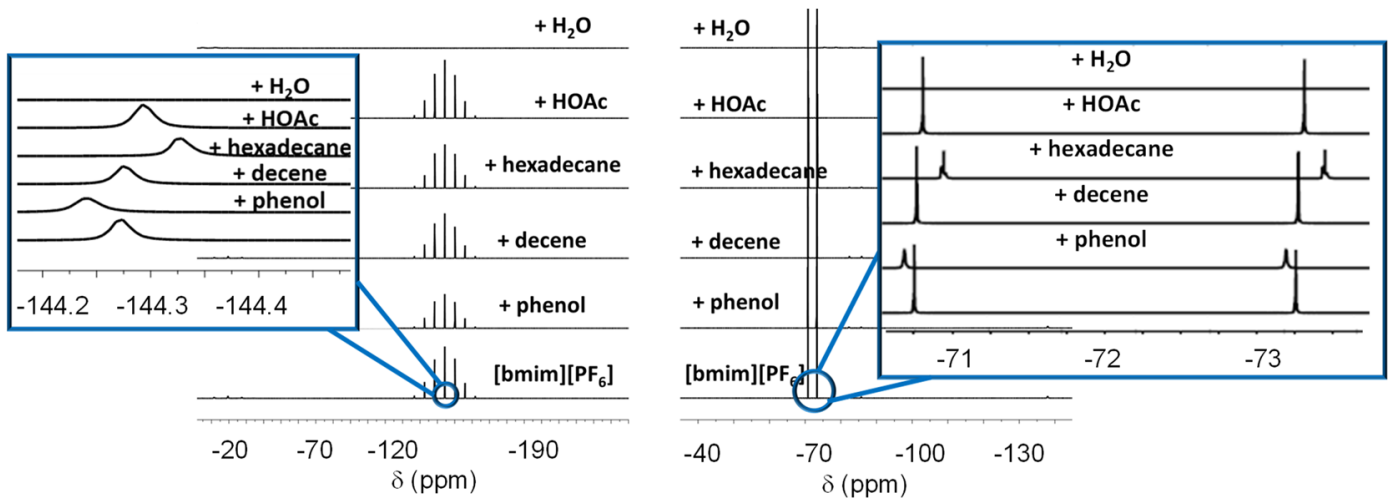

Figure 3. ${ }^{31} \mathrm{P}$ - (left) and ${ }^{19} \mathrm{~F}-\mathrm{NMR}$ study (right) of $[\mathrm{bmim}]\left[\mathrm{PF}_{6}\right]$ in the presence of different additives $\left(0.5\right.$ vol \%) after heating at $150{ }^{\circ} \mathrm{C}$. (insets) Magnification of the diagnostic areas, where the displacement exerted by $n$-hexadecane on the corresponding signals can be seen.

These microemulsions are very sensitive to $\mathrm{pH}$ fluctuations and, thus, are not suitable for strong acid catalysis. ${ }^{32}$ However, we have found by serendipity, while employing tiny amounts $(<1$ vol \%) of long linear carbon alkyl chain $n$-alkane as internal standards during catalyzed reactions in ILs that surfactants are not needed to generate well-dispersed alkane microdomains within the IL structure. At $<1$ vol \%, the higher surface tension, good packaging, and higher number of vander-Waals forces in the long linear alkane (compared with shorter derivatives) provide enough enthalpic energy to selfstabilize the aggregates, ${ }^{33}$ in good accordance with recent reports on self-stabilized and surfactant-free water-in-IL ${ }^{34-38}$ and water-in-alkane mixtures. ${ }^{39}$ Remarkably, the apolar/polar microstructured media can sufficiently separate the ion pair to impart catalytic behavior. ${ }^{40,41}$ The homogeneously distributed microdomains unleash the acidity of the IL to trigger strong Lewis acid-catalyzed organic reactions, i.e. the Friedel-Crafts alkylation of phenol. It will also be shown here that, in a similar way, water generates well-defined microdroplets to turn the IL into a powerful Brönsted acid catalyst. ${ }^{42-46}$

\section{EXPERIMENTAL SECTION}

\section{General Procedure for Alkylation of Phenol in Ionic Liquids}

Phenol ( $2 \mathrm{mmol}$ ) was dissolved in $2 \mathrm{~mL}$ of 1-butyl-3-methylimidazolium hexafluorophosphate $\left([\mathrm{bmim}]\left[\mathrm{PF}_{6}\right]\right.$; see Table $\mathrm{S} 1$ for a complete description of the ILs used in this work), and 1-decene $(0.25 \mathrm{mmol})$ was then added to the solution, followed by $n$ hexadecane $(0.5 \mathrm{vol} \%)$. The sealed reaction tube, equipped with a magnetic bar, was stirred at $750 \mathrm{rpm}$ in a preheated oil bath at $150{ }^{\circ} \mathrm{C}$ for $16 \mathrm{~h}$. After cooling, the reaction mixture was extracted with diethyl ether $(3 \times 4 \mathrm{~mL})$ and analyzed by GC, GC-MS, and NMR in order to identify and quantify the products, using the added $n$-hexadecane as an internal standard. For kinetics, each point was taken from an individual reaction.

\section{General Procedure for the tert-Butylation of Alcohols}

The corresponding alcohol $(0.1 \mathrm{mmol})$ and $\mathrm{AcO}^{t} \mathrm{Bu}(0.15 \mathrm{mmol})$ were added under ambient conditions to an aqueous dispersion ( 5 vol $\%)$ in 1-butyl-3-methylimidazolium tetrafluoroborate $[\mathrm{bmim}]\left[\mathrm{BF}_{4}\right]$, in a sealed tube containing a magnetic bar, and the mixture was stirred in a preheated oil bath at $75{ }^{\circ} \mathrm{C}$ during $2 \mathrm{~h}$. Then, the reaction mixture was cooled and extracted with diethyl ether $(1.5 \mathrm{~mL})$. The extracts were analyzed by GC, GC-MS, and NMR after adding $n$-dodecane $(22.4 \mu \mathrm{L}, 0.2 \mathrm{mmol})$ as an external standard.

\section{RESULTS AND DISCUSSION}

\section{Generation of $n$-Alkane Microdomains in ILs}

Figure 2 shows optical microphotographs of the benchmark IL $[\mathrm{bmim}]\left[\mathrm{PF}_{6}\right]$ after addition of different $n$-alkanes ( 0.5 vol \%) and heating at $150{ }^{\circ} \mathrm{C}$ for $1 \mathrm{~h}$. The formation of well-dispersed microdomains can be observed for long alkanes $\left(>\mathrm{C}_{12}\right)$. No microdomain formation occurs at room temperature $\left(25{ }^{\circ} \mathrm{C}\right.$, Figure S1) and the addition of $>1.5$ vol \% of $n$-alkane drastically reduces the homogeneity of the alkane microdomain (Figure S2). The concomitant addition of other additives such as $\mathrm{H}_{3} \mathrm{PO}_{4}, 1$-decene, and 1-decanol does not significantly alter the microdomain formation in many cases (Figure S3). Residual water in the starting IL has no influence in the microdroplet formation.

The formation of microdomains in the IL can be explained by the increasing interfacial tension with the $n$-alkane length, which is calculated by the Girifalco and Good equation: $\gamma^{\mathrm{AB}}=$ $\gamma^{\mathrm{A}}+\gamma^{\mathrm{B}}-2 \Phi\left(\gamma^{\mathrm{A}} \gamma^{\mathrm{B}}\right)^{1 / 2}$ (where $\gamma$ is the surface tension at the working temperature for each component and $\Phi$ is a characteristic constant of the system, which can be determined either experimental and theoretically; see Figure S4 for calculations). ${ }^{47,48}$ The mixture of the highly polar but soft IL with the apolar, extremely soft $\mathrm{C}_{14-18} n$-alkanes, generates a calculated interfacial tension $\gamma^{\mathrm{AB}}>15 \mathrm{mN} \cdot \mathrm{m}^{-1}$, which is within 
the accepted values to spontaneously generate stable microdroplets in liquid-liquid mixtures. ${ }^{49-52}$ The slight decrease of interfacial tension produced by the increasing temperature is apparently compensated by the higher mobility of the organic molecules in the IL, to give the final microstructured IL/alkane material. $^{53}$

Figure 3 shows the ${ }^{31} \mathrm{P}$ - and ${ }^{19} \mathrm{~F}$-nuclear magnetic resonance (NMR) spectra of $[\mathrm{bmim}]\left[\mathrm{PF}_{6}\right]$ in the presence of different additives after heating at $150{ }^{\circ} \mathrm{C}$, including $n$-hexadecane. Samples were prepared in $\mathrm{CD}_{3} \mathrm{CN}$, where the microdroplets retain their integrity according to microimages and by a parallel experiment with a capillary NMR tube where both the $\mathrm{IL}$ and the $\mathrm{CD}_{3} \mathrm{CN}$ phases are physically separated (Figure S5). The results clearly show that only $n$-hexadecane and not the rest of additives produces a downshift in the original ${ }^{31} \mathrm{P}$ and ${ }^{19} \mathrm{~F}$ signals of $\mathrm{PF}_{6}{ }^{-}$, which means that the $\mathrm{PF}_{6}^{-}$anion is gaining electron density or, in other words, that the ammonium cation bmim $^{+}$is becoming more electrophilic and acid. Notice that the downshift of the NMR signals does not occur at $25{ }^{\circ} \mathrm{C}$, when the microdomains are still poorly defined (Figures S6-S7). The cyclic voltammogram at $\mathrm{Pt}$ electrode of $[\mathrm{bmim}]\left[\mathrm{PF}_{6}\right]$ (Figure S8) shows that a clear enhancement of the signals with a dramatic decrease in the original onset potential of the IL (from 1.8 to ca. $1.2 \mathrm{eV}$ ) occurs after the addition of $n$-tetradecane ( 0.25 vol \%, black line), which is consistent with the formation of new cationic species in the IL. ${ }^{54}$

In order to confirm the acidification of $[\mathrm{bmim}]\left[\mathrm{PF}_{6}\right]$ after the addition of long chain $n$-alkanes, trimethylphosphine oxide (TMPO) was used as a probe molecule and the acidity change was evaluated by ${ }^{31} \mathrm{P}-\mathrm{NMR}$. The results show that the IL gains some acidity after the addition of $n$-hexadecane, since two new TMPO ${ }^{31}$ P-NMR signals upshifted respect to the neat IL (39.8 and 39.4 vs $39.3 \mathrm{ppm}$ ), appear (Figure S9). Despite these values being far from those reported for BAILs and LAILs, ${ }^{55-57}$ they are in line with the acidification of the IL after alkane addition and, moreover, the appearance of a first broad signal and a second signal as narrow as the original TMPO signal, suggests the formation of both Lewis and Brönsted acid sites, respectively. ${ }^{57}$ These results suggest the generation of polarized ionic pairs in $[\mathrm{bmim}]\left[\mathrm{PF}_{6}\right]$ after the addition of long $n$-alkanes, which may be now employed as Lewis catalysts for organic reactions.

\section{Catalytic Alkylation of Phenol}

Figure 4 shows the results in $n$-alkane/IL mixtures of the Friedel-Crafts alkylation of phenol with 1-decene, an industrially relevant organic reaction typically catalyzed by very strong Lewis acids (i.e., $\left.\mathrm{AlCl}_{3}\right)^{58-60}$ and where charge separation in the reaction media can be beneficial. ${ }^{61,62}$ The alkylation proceeds in $>95 \%$ conversion and selectivity toward the desired carbon-alkylated products only when $n$-alkanes, able to generate the microdomains $\left(\mathrm{C}_{14}\right.$ or longer $)$, are added to the IL, even highly branched (Figure S10). In contrast, the reaction conversion dramatically decreases if shorter alkanes are used, and also if the amount of $n$-alkane is too large to generate the microdomains (>1.5 vol \%, Figures S11-S12), which is evidenced by the stopping of the reaction in the primary oxygen-alkylated product and the formation of degradation products at complete conversion. ${ }^{63}$ In accordance with this, only specially designed BAILs have been reported to catalyze this reaction; otherwise, the Friedel-Crafts alkylation of phenol does not work in any conventional IL. ${ }^{64}$ These results strongly support a direct connection between alkane microdomains and strong Lewis acidity in the IL.

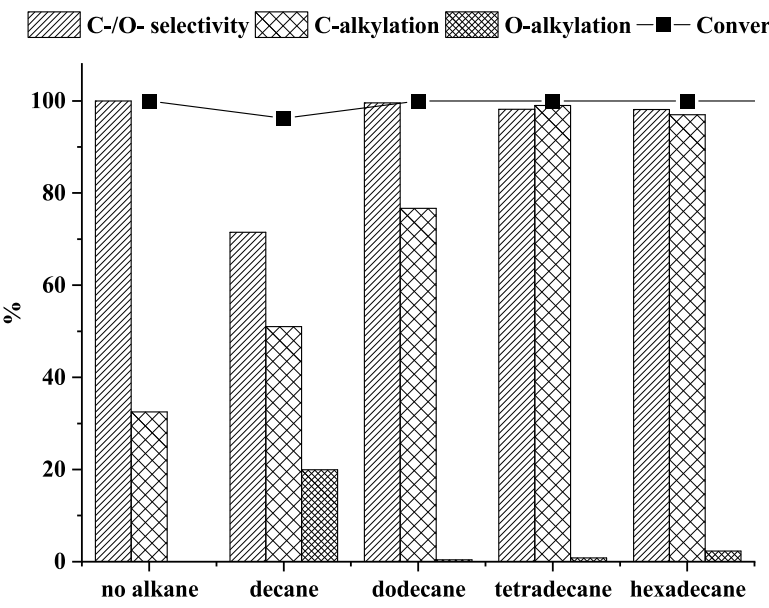

Figure 4. Catalytic results for the alkylation of phenol with 1-decene to give decyl phenol.

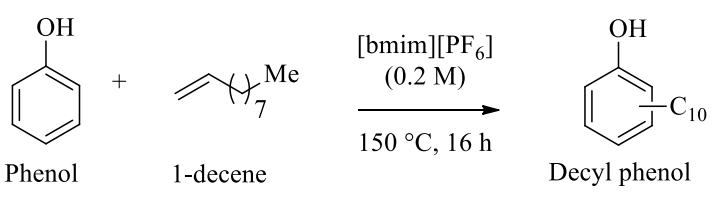

Kinetic experiments (Figure S13) show that the alkylation reaction follows the rate equation $v_{0}=k_{\exp }[n$-alkane $][1$ decene $][\text { phenol }]^{2}$ at low concentrations, which is in good agreement with the initial formation of the $\mathrm{O}$-alkylated product followed by a trans-C-alkylation to a second phenol molecule. Control experiments were then carried out in order to discard any Brönsted catalysis that may be promoted by hydrolysis of $[\mathrm{bmim}]\left[\mathrm{PF}_{6}\right]$ under reaction conditions. First, optical microphotographs discard the significant formation of microdomains not only in phenol/ $[\mathrm{bmim}]\left[\mathrm{PF}_{6}\right]$ mixtures but also after addition of other alcohols (Figure S14), which infers that the alcohols are in the IL phase. However, the stirring rate has a positive influence on the catalytic reaction, in accordance with the limited mobility of organic substances in the IL (Table S2). Second, the alkylation reaction was attempted with typical strong Brönsted acids such as $\mathrm{H}_{3} \mathrm{PO}_{4}$, HOTf (triflic acid), and HF (the typical acid byproduct of hydrolysis) and the alkylation proceeded in $<50 \%$ conversions (Figure S15), even if neat water is added. These low conversions are partially palliated if $n$-hexadecane is added (Figure S15), which strongly supports the independent action of the alkane respect to the Brönsted acid. The same independent and enhanced catalytic effect of $n$-hexadecane was observed for typical Lewis acid and solid catalysts such as $\mathrm{AlCl}_{3}, \mathrm{FeCl}_{3}$, zeolite $\mathrm{HY}$, and amberlyst A15 (Figure S16). Besides, if the IL 1-butyl-3methymethylimidazolium hexafluorophosphate [bmmim]$\left[\mathrm{PF}_{6}\right]$ is used instead of $[\mathrm{bmim}]\left[\mathrm{PF}_{6}\right]$, where the acidic proton in the C-2 position of the imidazolium ring has been substituted by a methyl group, the alkylation proceeds in similar good conversions (Figure S17), which discards any catalytic action of the C-2 hydrogen. ${ }^{65}$ Indeed, 11 different ILs were tested for the reaction and all those containing the $\mathrm{PF}_{6}$ anion were very active and selective, only mimicked by one LAIL and one BAIL, while coline-based ILs were completely inactive (Figure S17). The use of mesitylene as a cosolvent, 

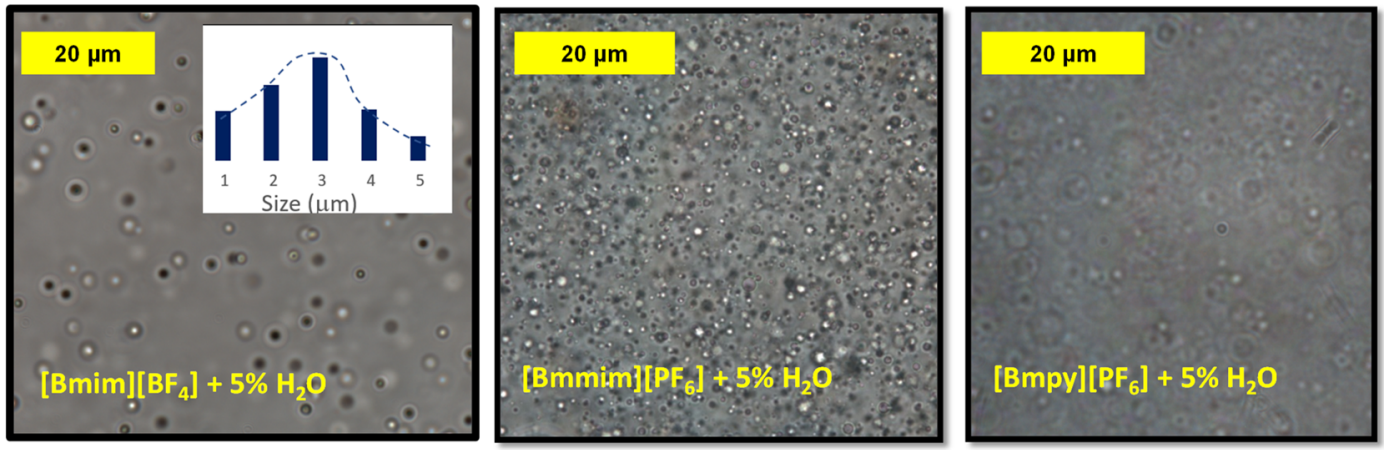

Figure 5. Optical microphotographs of different ILs in the presence of water $(5 \mathrm{vol} \%)$ at $25{ }^{\circ} \mathrm{C}$. (inset) Representative histogram with $>1000$ microdroplets.

A)

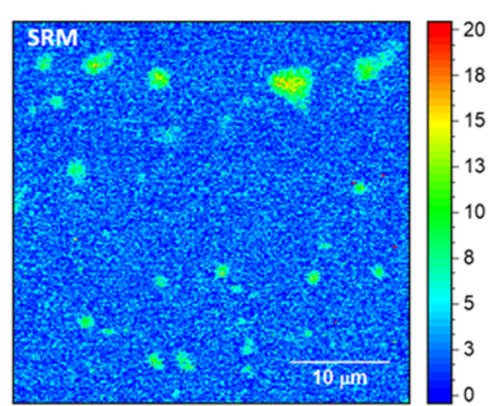

B)

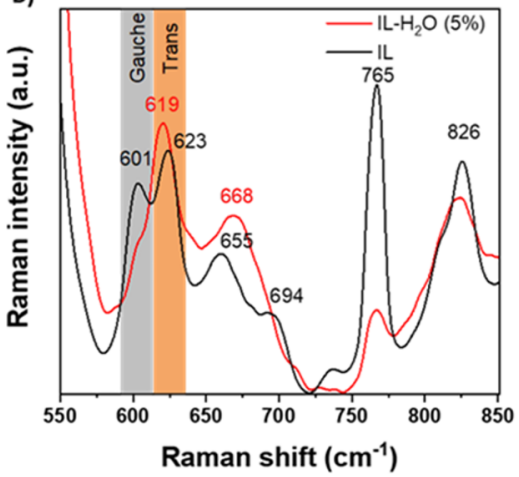

C)
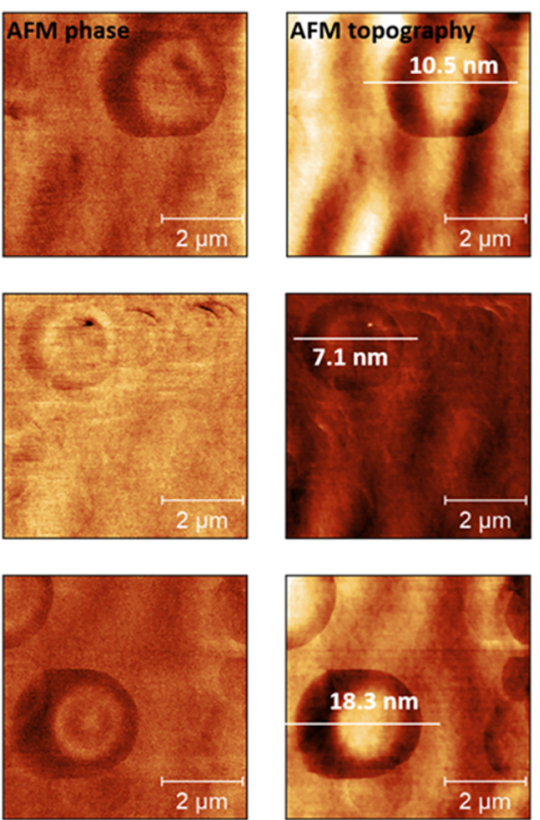

Figure 6. (A) Scanning Raman map of a $[\mathrm{bmim}]\left[\mathrm{BF}_{4}\right]-\mathrm{H}_{2} \mathrm{O}(5 \mathrm{vol} \%)$ mixture $\left(\mathrm{IL}-\mathrm{H}_{2} \mathrm{O}\right)$. The signal from the blue background corresponds to the characteristic Raman active modes of the IL (range 601-623 cm $\mathrm{cm}^{-1}$ ), and the greenish circles correspond to IL- $\mathrm{H}_{2} \mathrm{O}$ aggregates. (B) Raman mean spectra of IL (black line) and $\mathrm{IL}-\mathrm{H}_{2} \mathrm{O}$ aggregates (red line) highlighting the gauche to trans conformation change observed in IL alkyl chains of the aggregates after water addition. (C) Noncontact soft tapping mode AFM phase (left) and topography (right) images of several IL- $\mathrm{H}_{2} \mathrm{O}$ aggregates laying on an IL background.

which destroys the microdomains, completely inhibits the reaction, even adding an external Brönsted acid such as $\mathrm{AcOH}$ (Figure S18). These results together confirm that the acid catalysis does not come from in situ generated protons in the IL. Indeed, the IL could be recycled up to three times, although with some loss of catalytic activity throughout the reuses, despite adding $n$-hexadecane in each cycle (Figure S19). When increasing amounts of 2,6-di-tert-butylpyridine (DTBP) and pyridine (py) were used as Brönsted and Brönsted/Lewis acidity probes, respectively, during reaction, the catalytic activity decreased significantly with the amounts of pyridines (Figure S20). DTBP produced catalytic deactivation until reaching a plateau at $\sim 50 \%$ conversion, in accordance with its selective quenching of protons but not of Lewis species. In contrast, py produced a smoother deactivation to nearly suppress any catalytic activity, in accordance with the quenching of Lewis and also Brönsted catalytic sites. These results indicate that the catalytic activity of the $[\mathrm{bmim}]\left[\mathrm{PF}_{6}\right] / n$-hexadecane system comes basically from Lewis sites but that a no marginal contribution of Brönsted sites occurs.

Other representative ammonium ionic liquids such $\mathrm{N}$-butyl4-methylpyridinium hexafluorophosphate $[\mathrm{bmpy}]\left[\mathrm{PF}_{6}\right]$ also generate the microdroplets after $n$-hexadecane addition and catalyzes the alkylation reaction (Figure S17). In contrast, the substitution of the $\mathrm{PF}_{6}^{-}$anion by $\mathrm{BF}_{4}^{-}$or $\mathrm{TFSI}^{-}$completely inhibits the microdroplet formation, in accordance with the catalytic results (Figure S17), which can be tentatively ascribed to a much more hydrophilicity of the latter, thus changing the subtle charge balance in the alkane/IL system. Indeed, it is difficult to firmly assess the phase location of the reagents, particularly the alkene. However, in view of the very specific correlation between the anion of the IL and the alkane to generate the microdomains, we studied the possible formation 

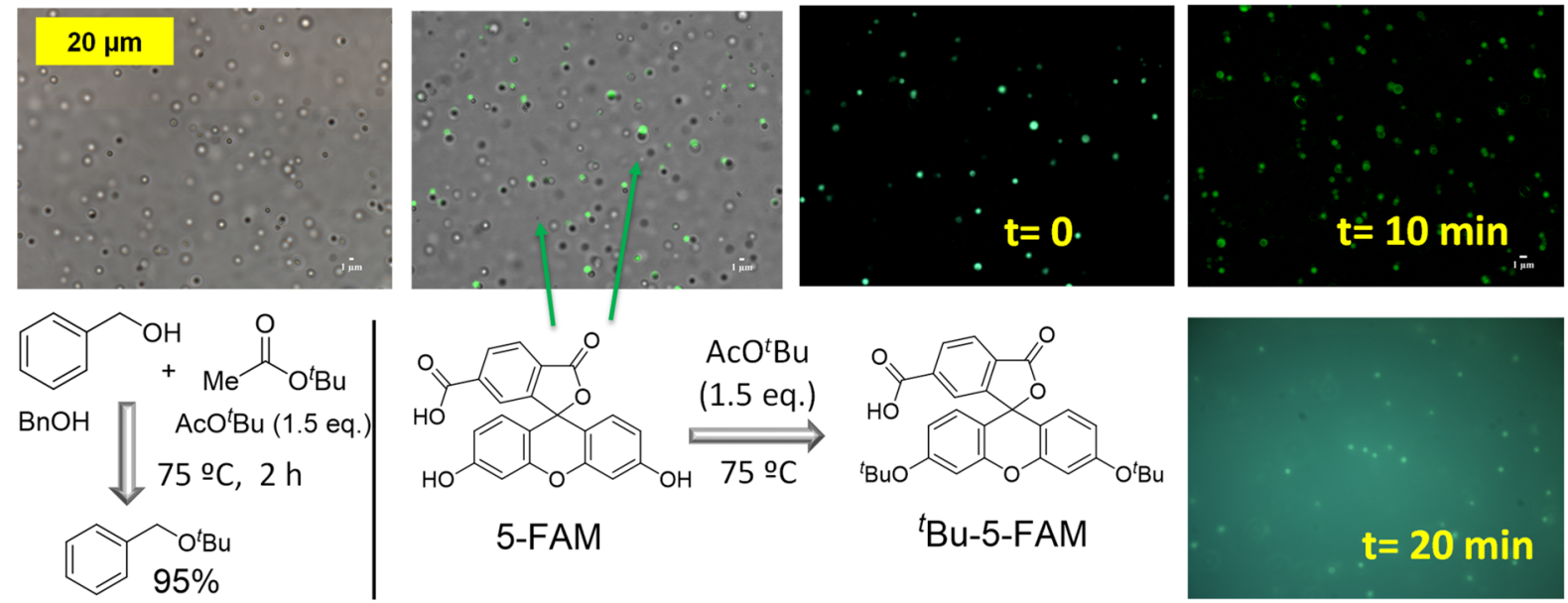

Figure 7. (from left to right) Nonfluorescence and fluorescence optical microscopy images of the acid-catalyzed tert-butylation of benzyl alcohol with aqueous microdroplets in $[$ bmim $]\left[\mathrm{BF}_{4}\right]$ at $75{ }^{\circ} \mathrm{C}$ (reaction scheme and conversion also shown), followed in situ by using carboxyflourescein (5-FAM) as a reactant.

of microdomains with a polar molecule such as water, by changing the IL employed.

\section{Generation of Well-Defined Water Microdroplets}

Figure 5 shows microphotographs of the homogeneous formation of microdroplets when water ( $5 \mathrm{vol} \%)$ was added to different ILs at room temperature. ${ }^{34,35}$ The formation of the microdroplets is immediate, as soon as water is added, and the amount of water can vary from 2 to 5 vol \% with a constant microdroplet size distribution centered at $2.8 \mu \mathrm{m}$ (see Figure S21 for a bigger image).

To further characterize the $\mathrm{IL}-\mathrm{H}_{2} \mathrm{O}$ microdroplets, scanning Raman microscopy (SRM) was performed on a [bmim]$\left[\mathrm{BF}_{4}\right]-\mathrm{H}_{2} \mathrm{O}(5 \%)$ mixture, drop-casted on $\mathrm{Si} / \mathrm{SiO}_{2}$ wafers using previously purified $[\mathrm{bmim}]\left[\mathrm{BF}_{4}\right]\left(<0.1 \mathrm{ppm}\right.$ of $\mathrm{O}_{2},<10$ ppm of $\left.\mathrm{H}_{2} \mathrm{O}\right)$ as a reference. Figure $6 \mathrm{~A}$ contains a $50 \mu \mathrm{m} \times 50$ $\mu \mathrm{m}$ SRM images where the Raman active modes are between 601 and $623 \mathrm{~cm}^{-1}$ (indicative of the butyl chain conformation, i.e., gauche and trans forms) are observed. It has been predicted $^{66}$ that different nanostructures could be formed depending on the $\mathrm{H}_{2} \mathrm{O}$ :IL composition and that the coordination of water molecules with the $\mathrm{BF}_{4}{ }^{-}$will shift the anion from the initial position, inducing changes in the chain conformation of the cation that should be reflected in the conformation around the $\mathrm{C}(7)-\mathrm{C}(8)$ bond of the IL butyl chain.

Specifically, this change will consist in the transformation from a mixture of trans/gauche configuration with similar strengths (IL, black spectra) to a predominant trans configuration ( $\mathrm{IL}-\mathrm{H}_{2} \mathrm{O}$, red spectra). Figure $6 \mathrm{~B}$ shows that the aggregates can be clearly recognized in the Raman mean spectra, with different active bands (see also Figures S22-24). Figure 6C shows atomic force microscopy (AFM) measurements in noncontact soft tapping mode (see also Figure S24), where the phase and topography images present round microstructures ranging from 1 to $2.5 \mu \mathrm{m}$ in diameter and up to $70 \mathrm{~nm}$ in height, embedded on an IL layer, and with a morphology very similar to optical microscopy (see Figure 5 above). It is important to note that these values offer just an estimation of the dimensions and are strongly affected by the wavy background, produced by the IL layer that coats the underlying wafer. The doughnutlike shape observed in the phase images is explained by the force that the AFM tip induces on the microdroplets. Overall, AFM and SRM unambiguously confirm the formation of $\mathrm{IL}-\mathrm{H}_{2} \mathrm{O}$ microdroplets and provide some hints about the charge transfer from the IL anions to the water molecules, leading to a drastic charge separation.

The IL- $\mathrm{H}_{2} \mathrm{O}$ mixture can be heated up to $100{ }^{\circ} \mathrm{C}$ without any loss in microdroplet size, as assessed by field emission scanning electron microscopy (FESEM, Figure S25), while further heating up to $150{ }^{\circ} \mathrm{C}$ produces the decomposition of the IL, as evidenced not only by FESEM visualizations but also by ${ }^{31} \mathrm{P}$ - and ${ }^{19} \mathrm{~F}-\mathrm{NMR}$ spectra (Figures S6-S7). For amounts of water $>5$ vol \%, microdroplets seem to aggregate in still defined microdomains, which remain spread over the IL and do not separate in a two phase system, as determined by AFM measurements where the height of the water aggregates remains within the IL film limits (Figure S26A). ${ }^{34,35}$ Fouriertransformed infrared (FT-IR) spectroscopy shows that increasing amounts of water produces a progressive shift of the corresponding signal toward higher wavenumber values, in accordance with the aggregation of the separated microdroplets (Figure S26B). ${ }^{67,68}$

\section{Catalytic tert-Butylation of Alcohols}

With the above data in mind, a representative organic reaction catalyzed by strong Brönsted acids, i.e. the tert-butylation of $\mathrm{BnOH}$ with tert-butyl acetate $\left(\mathrm{AcO}^{t} \mathrm{Bu}\right),{ }^{69}$ was tested under the acid aqueous/[bmim $]\left[\mathrm{BF}_{4}\right]$ conditions shown above. It was previously checked that the reactant benzyl alcohol $(\mathrm{BnOH})$ do not generate microdomains, but rather hierarchically structured macrodomains which do not interfere in the water action (Figure S27). ${ }^{70}$ Indeed, the addition of $1 \mathrm{vol} \%$ of neat water or aqueous $\mathrm{H}_{3} \mathrm{PO}_{4} / \mathrm{K}_{3} \mathrm{PO}_{4}$ to the IL/benzyl alcohol mixture generates the microdroplets without any alteration (Figure S28). Figure 7 shows that the reaction proceeds in high conversion and with good selectivity toward the Calkylated rather than the O-alkylated product and that if the reaction is performed with the water-soluble and fluorescent molecule carboxyfluorescein (5-FAM) ${ }^{71}$ and monitored by insitu fluorescence optical microscopy, the starting material reacts within the aqueous droplets, at least during the first 10 min and until the organic compounds start to diffuse into the IL bulk. Notice that the bright and dark field images superimpose perfectly, beyond the natural movement of the 
liquid film, thus particular microdroplets can be followed during the in-situ monitored tert-butylation reaction (see Figure S29 for bigger images), and it can be said that the initial location of 5-FAM is the water phase. Blank experiments showed that the released HOAc does not catalyze the reaction (not shown). 5-FAM was also used as a $\mathrm{pH}$-dependent probe, and the results show that the emission of 5-FAM shifts toward higher values after incorporation into the aqueous IL microdroplets, which according to a calibration curve corresponds to a very acid $\mathrm{pH}$ (Figure S30), within the limitations of the available illuminating wavelengths. TMPO as an acid probe confirmed the acidification of the IL in the form of Bröntsed species (Figure S9). ${ }^{55-57}$ Cyclic voltammograms of $[\mathrm{bmim}]\left[\mathrm{BF}_{4}\right]$ show a clear current enhancement and a considerable positive shift of around $400 \mathrm{mV}$ in the onset potential after the addition of $1.5 \mathrm{vol} \%$ water, and both effects increase with the percentage of water, until the hydrogen evolution reaction occurs and the production of $\mathrm{H}_{2}$ bubbles on the electrode surface produces an irregular current record (Figure S31). ${ }^{72,73}$ These results, together, strongly support the formation of very strong catalytic acid sites in the water microdroplets of the more hydrophilic $\left[\mathrm{bmim}^{2}\right]\left[\mathrm{BF}_{4}\right] \mathrm{IL}^{74} \mathrm{It}$ must be noted here that the high density of water microdroplets in the IL significantly increases the surface area of the IL in contact with water, since a simple calculation leads to a value of $480 \mathrm{~m}^{2} \cdot \mathrm{mL}^{-1}$ of IL (Figure S32). This result suggests that the increase in surface could also be behind the enhanced catalytic activity.

\section{CONCLUSIONS}

The addition of tiny amounts of long $n$-alkanes or water to conventional ILs spontaneously generates well-defined superficial alkane microdomains or water spherical microdroplets with Lewis and Brönsted acid catalytic sites, after polarization of the IL structure. This extremely simple protocol circumvents any chemical modification or significant degradation of the IL and provides an extremely mild, easy, and cheap methodology to acidify and microstructure ILs.

The surface area is significantly increased, which promises new applications not only in catalysis but also in material synthesis and chemistry in confined spaces, to name a few. The potential extension of this effect to other polar solvents is also a relevant issue to be studied.

\section{ASSOCIATED CONTENT}

\section{Supporting Information}

The Supporting Information is available free of charge at https://pubs.acs.org/doi/10.1021/jacsau.1c00107.

Additional experimental data and Tables S1-S2 and Figures S1-S32 (PDF)

\section{AUTHOR INFORMATION}

\section{Corresponding Authors}

Gonzalo Abellán - Instituto de Ciencia Molecular (ICMol), Universitat de Valencia, 46980 Paterna, Valencia, Spain; (1) orcid.org/0000-0003-1564-6210;

Phone: +34963544074; Email: gonzalo.abellan@uv.es; Fax: +34963543273

Antonio Leyva-Pérez - Instituto de Tecnología Química, Universidad Politècnica de Valencia-Consejo Superior de Investigaciones Científicas,, 46022 Valencia, Spain;
두 orcid.org/0000-0003-1063-5811; Phone: +34963877800; Email: anleyva@itq.upv.es; Fax: +34963877809

\section{Authors}

Rossella Greco - Instituto de Tecnología Química, Universidad Politècnica de Valencia-Consejo Superior de Investigaciones Científicas, 46022 Valencia, Spain

Vicent Lloret - Department of Chemistry and Pharmacy, Friedrich-Alexander-Universität Erlangen-Nürnberg (FAU), 91054 Erlangen, Germany; Joint Institute of Advanced Materials and Processes (ZMP), Friedrich-Alexander-Universität Erlangen-Nürnberg (FAU), 90762 Fürth, Germany

Miguel Angel Rivero-Crespo - Instituto de Tecnología Química, Universidad Politècnica de Vatencia-Consejo Superior de Investigaciones Científicas,, 46022 Valencia, Spain

Andreas Hirsch - Department of Chemistry and Pharmacy, Friedrich-Alexander-Universität Erlangen-Nürnberg (FAU), 91054 Erlangen, Germany; Joint Institute of Advanced Materials and Processes (ZMP), Friedrich-Alexander-Universität Erlangen-Nürnberg (FAU), 90762 Fürth, Germany; 이이.org/0000-00031458-8872

Antonio Doménech-Carbó - Departament de Química Analítica, Universitat de Valencia, 46100 Burjassot, Vatencia, Spain; (1) orcid.org/0000-0002-5284-2811

Complete contact information is available at: https://pubs.acs.org/10.1021/jacsau.1c00107

\section{Author Contributions}

R.G. found the key discovery about the $n$-alkane effect in the IL and performed the characterization and catalytic studies. V.Ll. performed the Raman and AFM measurements. A.H. supervised some characterization experiments and revised the manuscript. M.A.R.-C. found the water microdroplets in the IL and performed characterization studies. A.D.-C. performed and interpreted the voltammetry experiments. G.A. supervised the characterization part and wrote the manuscript. A.L.-P. performed catalytic experiments, supervised the whole project, and wrote the manuscript. All authors have given approval to the final version of the manuscript.

Funding

Financial support by Spanish MICINN through the Severo Ochoa program (SEV-2016-0683) and Unit of Excellence "Maria de Maeztu" (CEX2019-000919-M) and also the Excellence program (CTQ 2017-86735-P, PID2019111742 GA-I00) is acknowledged. This work has been supported by the European Research Council (ERC Starting Grant no. 2D-PnictoChem 804110 to G.A. and ERC Advanced Grant 742145 B-PhosphoChem to A.H.), the Generalitat Valenciana (CIDEGENT/2018/001 to G.A. and iDiFEDER/ 2018/061), and the Deutsche Forschungsgemeinschaft (DFG, FLAG-ERA AB694/2-1).

Notes

The authors declare no competing financial interest.

\section{ACKNOWLEDGMENTS}

R.G. thanks the ITQ and Severo Ochoa program for the concession of a fellowship. M.A.R.-C. thanks MINECO for the 
concession of an FPU fellowship. We thank Prof. Hans-Peter Steinrück, Dr. Florian Maier, and Bettina Heller for fruitful discussions and José M. Coll-Marqués for performing the microfluorescence measurements.

\section{REFERENCES}

(1) Cremer, T.; Kolbeck, C.; Lovelock, K. R. J.; Paape, N.; Wölfel, R.; Schulz, P. S.; Wasserscheid, P.; Weber, H.; Thar, J.; Kirchner, B.; Maier, F.; Steinrück, H.-P. Towards a molecular understanding of cation-anion interactions-probing the electronic structure of imidazolium ionic liquids by NMR spectroscopy, $\mathrm{X}$-ray photoelectron spectroscopy and theoretical calculations. Chem. - Eur. J. 2010, 16, 9018-9033.

(2) Egorova, K. S.; Gordeev, E. G.; Ananikov, V. P. Biological activity of ionic liquids and their application in pharmaceutics and medicine. Chem. Rev. 2017, 117, 7132-7189.

(3) Zanatta, M.; Simon, N. M.; Dupont, J. The nature of carbon dioxide in bare ionic liquids. ChemSusChem 2020, 13, 3101-3109.

(4) Olah, G. A. Crossing conventional boundaries in half a century of research. J. Org. Chem. 2005, 70, 2413-2429.

(5) Antoniotti, S.; Dalla, V.; Duñach, E. Metal triflimidates: better than metal triflates as catalysts in organic synthesis-the effect of a highly delocalized counteranion. Angew. Chem., Int. Ed. 2010, 49, 7860-7888.

(6) Cabrero-Antonino, J. R.; Leyva-Pérez, A.; Corma, A. Beyond acid strength in zeolites: soft framework counteranions for stabilization of carbocations on zeolites and its implication in organic synthesis. Angew. Chem., Int. Ed. 2015, 54, 5658-5661.

(7) Cabrero-Antonino, J. R.; Tejeda-Serrano, M.; Quesada, M.; Vidal-Moya, J. A.; Leyva-Perez, A.; Corma, A. Bimetallic nanosized solids with acid and redox properties for catalytic activation of $\mathrm{C}-\mathrm{C}$ and $\mathrm{C}-\mathrm{H}$ bonds. Chem. Sci. 2017, 8, 689-696.

(8) Blasco, T.; Corma, A.; Iborra, S.; Lezcano-Gonzalez, I.; Monton, R. In situ multinuclear solid-state NMR spectroscopy study of Beckmann rearrangement of cyclododecanone oxime in ionic liquids: The nature of catalytic sites. J. Catal. 2010, 275, 78-83.

(9) Freire, M. G.; Neves, C. M. S. S.; Marrucho, I. M.; Coutinho, J. A. P.; Fernandes, A. M. Hydrolysis of tetrafluoroborate and hexafluorophosphate counter ions in imidazolium-based ionic liquids. J. Phys. Chem. A 2010, 114, 3744-3749.

(10) Huang, H.; Zhong, J.; Tan, X.; Guo, X.; Yuan, B.; Lin, Y.; Francisco, J. S.; Zeng, X. C. New insights into the stability of anhydrous $2 \mathrm{H}$-imidazolium fluoride and its high dissolution capability toward a strongly hydrogen-bonded compound. J. Am. Chem. Soc. 2020, 142, 10314-10318.

(11) Sievers, C.; Musin, I.; Marzialetti, T.; Valenzuela Olarte, M. B.; Agrawal, P. K.; Jones, C. W. Acid-catalyzed conversion of sugars and furfurals in an ionic-liquid phase. ChemSusChem 2009, 2, 665-671.

(12) Karakulina, A.; Gopakumar, A.; Akcok, I.; Roulier, B. L.; LaGrange, T.; Katsyuba, S. A.; Das, S.; Dyson, P. J. A rhodium nanoparticle-lewis acidic ionic liquid catalyst for the chemoselective reduction of heteroarenes. Angew. Chem., Int. Ed. 2016, 55, 292-296.

(13) Offner-Marko, L.; Bordet, A.; Moos, G.; Tricard, S.; Rengshausen, S.; Chaudret, B.; Luska, K. L.; Leitner, W. Bimetallic nanoparticles in supported ionic liquid phases as multifunctional catalysts for the selective hydrodeoxygenation of aromatic substrates. Angew. Chem., Int. Ed. 2018, 57, 12721-12726.

(14) Luska, K. L.; Migowski, P.; El Sayed, S.; Leitner, W. Synergistic interaction within bifunctional ruthenium nanoparticle/SILP catalysts for the selective hydrodeoxygenation of phenols. Angew. Chem., Int. Ed. 2015, 54, 15750-15755.

(15) Wang, Z.; Gao, F.; Ji, P.; Cheng, J. - P. Unexpected solvationstabilisation of ions in a protic ionic liquid: insights disclosed by a bond energetic study. Chem. Sci. 2018, 9, 3538-3543.

(16) Amarasekara, A. S. Acidic ionic liquids. Chem. Rev. 2016, 116, $6133-6183$
(17) Phipps, R. J.; Hamilton, G. L.; Toste, F. D. The progression of chiral anions from concepts to applications in asymmetric catalysis. Nat. Chem. 2012, 4, 603-614.

(18) Stassen, H. K.; Ludwig, R.; Wulf, A.; Dupont, J. Imidazolium salt ion pairs in solution. Chem. - Eur. J. 2015, 21, 8324-8335.

(19) Zong, L.; Tan, C. - H. Phase-transfer and ion-pairing catalysis of pentanidiums and bisguanidiniums. Acc. Chem. Res. 2017, $50,842-856$

(20) Qian, D.; Sun, J. Recent progress in asymmetric ion-pairing catalysis with ammonium salts. Chem. - Eur. J. 2019, 25, 3740-3751.

(21) Nishida, J.; Breen, J. P.; Wu, B.; Fayer, M. D. Extraordinary slowing of structural dynamics in thin films of a room temperature ionic liquid. ACS Cent. Sci. 2018, 4, 1065-1073.

(22) Xu, L.; Izgorodina, E. I.; Coote, M. L. Ordered solvents and ionic liquids can be harnessed for electrostatic catalysis. J. Am. Chem. Soc. 2020, 142, 12826-12833.

(23) Zaitsau, D. H.; Qyanenko, V. N. E.; Stange, P.; Verevkin, S. P.; Ludwig, R. Dissecting the vaporization enthalpies of ionic liquids by exclusively experimental methods: coulomb interaction, hydrogen bonding, and dispersion forces. Angew. Chem., Int. Ed. 2019, 58, 8589-8592.

(24) Yang, K.; Cai, Z.; Jaiswal, A.; Tyagi, M.; Moore, J. S.; Zhang, Y. Dynamic odd-even effect in liquid $\mathrm{n}$-alkanes near their melting points. Angew. Chem., Int. Ed. 2016, 55, 14090-14095.

(25) Canongia Lopes, J. N. A.; Pádua, A. A. H. Nanostructural organization in ionic liquids. J. Phys. Chem. B 2006, 110, 3330-3335.

(26) Zemb, T. N.; Klossek, M.; Lopian, T.; Marcus, J.; Schöettl, S.; Horinek, D.; Prevost, S. F.; Touraud, D.; Diat, O.; Marčelja, S.; Kunz, W. How to explain microemulsions formed by solvent mixtures without conventional surfactants. Proc. Natl. Acad. Sci. U. S. A. 2016, $113,4260-4265$.

(27) Anderson, J. L.; Pino, V.; Hagberg, E. C.; Sheares, V. V.; Armstrong, D. W. Surfactant solvation effects and micelle formation in ionic liquids. Chem. Commun. 2003, 2444-2445.

(28) Gao, Y.; Han, S.; Han, B.; Li, G.; Shen, D.; Li, Z.; Du, J.; Hou, W.; Zhang, G. TX-100/Water/1-Butyl-3-methylimidazolium hexafluorophosphate microemulsions. Langmuir 2005, 21, 56815684.

(29) Lian, Y.; Zhao, K. Study of micelles and microemulsions formed in a hydrophobic ionic liquid by a dielectric spectroscopy method. I. Interaction and percolation. Soft Matter 2011, 7, 88288837.

(30) Zhang, M.; Ettelaie, R.; Yan, T.; Zhang, S.; Cheng, F.; Binks, B. P.; Yang, H. Ionic liquid droplet microreactor for catalysis reactions not at equilibrium. J. Am. Chem. Soc. 2017, 139, 17387-17396.

(31) Guterman, R.; Molinari, V.; Josef, E. Ionic liquid lignosulfonate: dispersant and binder for preparation of biocomposite materials. Angew. Chem., Int. Ed. 2019, 58, 13044-13050.

(32) Hejazifar, M.; Earle, M.; Seddon, K. R.; Weber, S.; Zirbs, R.; Bica, K. Ionic liquid-based microemulsions in catalysis. J. Org. Chem. 2016, 81, 12332-12339.

(33) Almeida, H. F. D.; Freire, M. G.; Fernandes, A. M.; Lopes-daSilva, J. A.; Morgado, P.; Shimizu, K.; Filipe, E. J. M.; Canongia Lopes, J. N.; Santos, L. M. N. B. F.; Coutinho, J. A. P. Cation alkyl side chain length and symmetry effects on the surface tension of ionic liquids. Langmuir 2014, 30, 6408-6418.

(34) Kashin, A. S.; Galkin, K. I.; Khokhlova, E. A.; Ananikov, V. P. Direct observation of self-organized water-containing structures in the liquid phase and their influence on 5-(hydroxymethyl)furfural formation in ionic liquids. Angew. Chem., Int. Ed. 2016, 55, 21612166.

(35) Azov, V. A.; Egorova, K. S.; Seitkalieva, M. M.; Kashin, A. S.; Ananikov, V. P. Solvent-in-salt" systems for design of new materials in chemistry, biology and energy research. Chem. Soc. Rev. 2018, 47, $1250-1284$

(36) Spohr, H. V.; Patey, G. N. The influence of water on the structural and transport properties of model ionic liquids. J. Chem. Phys. 2010, 132, 234510. 
(37) Zhang, X.; Dong, H.; Bao, D.; Huang, Y.; Zhang, X.; Zhang, S. Effect of small amount of water on $\mathrm{co}_{2}$ droplet behavior in ionic liquid systems. Ind. Eng. Chem. Res. 2014, 53, 428-439.

(38) Cláudio, A. F. M.; Neves, M. C.; Shimizu, K.; Canongia Lopes, J. N.; Freire, M. G.; Coutinho, J. A. P. The magic of aqueous solutions of ionic liquids: ionic liquids as a powerful class of catanionic hydrotropes. Green Chem. 2015, 17, 3948-3963.

(39) Van Zee, N. J.; Adelizzi, B.; Mabesoone, M. F. J.; Meng, X.; Aloi, A.; Zha, R. H.; Lutz, M.; Filot, I. A. W.; Palmans, A. R. A.; Meijer, E. W. Potential enthalpic energy of water in oils exploited to control supramolecular structure. Nature 2018, 558, 100-103.

(40) Berrod, Q.; Ferdeghini, F.; Zanotti, J. - M.; Judeinstein, P.; Lairez, D.; García Sakai, V.; Czakkel, O.; Fouquet, P.; Constantin, D. Ionic liquids: evidence of the viscosity scale-dependence. Sci. Rep. 2017, 7, 2241-2248.

(41) Kashin, A. S.; Degtyareva, E. S.; Eremin, D. B.; Ananikov, V. P. Exploring the performance of nanostructured reagents with organicgroup-defined morphology in cross-coupling reaction. Nat. Commun. 2018, 9, 2936-2947.

(42) Macchieraldo, R.; Esser, L.; Elfgen, R.; Voepel, P.; Zahn, S.; Smarsly, B. M.; Kirchner, B. Hydrophilic ionic liquid mixtures of weakly and strongly coordinating anions with and without water. ACS Omega 2018, 3, 8567-8582.

(43) Dubouis, N.; Park, C.; Deschamps, M.; Abdelghani-Idrissi, S.; Kanduc, M.; Colin, A.; Salanne, M.; Dzubiella, J.; Grimaud, A.; Rotenberg, B. Chasing aqueous biphasic systems from simple salts by exploring the LiTFSI/LiCl/ $\mathrm{H}_{2} \mathrm{O}$ phase diagram. ACS Cent. Sci. 2019, $5,640-643$

(44) Luo, W.; Mao, C.; Ji, P.; Wu, J. - Y.; Yang, J. - D.; Cheng, J. P. Counterintuitive solvation effect of ionic-liquid/DMSO solvents on acidic $\mathrm{C}-\mathrm{H}$ dissociation and insight into respective solvation. Chem. Sci. 2020, 11, 3365-3370.

(45) Han, L.; Zheng, Y.; Luo, H.; Feng, J.; Engstler, R.; Xue, L.; Jing, G.; Deng, X.; del Campo, A.; Cui, J. Macroscopic self-evolution of dynamic hydrogels to create hollow interiors. Angew. Chem., Int. Ed. 2020, 59, 5611-5615.

(46) Dubouis, N.; Serva, A.; Berthin, R.; Jeanmairet, G.; Porcheron, B.; Salager, E.; Salanne, M.; Grimaud, A. Tuning water reduction through controlled nanoconfinement within an organic liquid matrix. Nat. Catal. 2020, 3, 656-663.

(47) Girifalco, L. A.; Good, R. J. A theory for the estimation of surface and interfacial energies. I. Derivation and application to interfacial tension. J. Phys. Chem. 1957, 61 (7), 904-909.

(48) Moneo, A.; Antón, V.; Martín, S.; Gascón, I.; Lafuente, C. Interfacial tensions of pyridinium-based ionic liquids and $\mathrm{n}$-alkanes or n-alkanols. J. Mol. Liq. 2018, 252, 469-474.

(49) Fitchett, B. D.; Rollins, J. B.; Conboy, J. C. Interfacial tension and electrocapillary measurements of the room temperature ionic liquid/aqueous interface. Langmuir 2005, 21, 12179-12186.

(50) Tuteja, A.; Choi, W.; Ma, M.; Mabry, J. M.; Mazzella, S. A.; Rutledge, G. C.; McKinley, G. H.; Cohen, R. E. Designing superoleophobic surfaces. Science 2007, 318, 1618-1622.

(51) Zhang, X. - J.; Wang, J. - Y.; Hu, Y. - Q. Interfacial Tension of n-alkane and ionic liquid systems. J. Chem. Eng. Data 2010, 55, 4687-4690.

(52) Needham, D.; Kinoshita, K.; Utoft, A. Micro-surface and interfacial tensions measured using the micropipette technique: applications in ultrasound-microdroplets, oil-recovery, lungsurfactants, nanoprecipitation, and microfluidics. Micromachines 2019, 10, 105-161.

(53) Heller, B. S. J.; Lexow, M.; Greco, F.; Shin, S.; Partl, G.; Maier, F.; Steinrück, H.-P. Temperature-dependent surface enrichment effects in binary mixtures of fluorinated and non-fluorinated ionic liquids. Chem. - Eur. J. 2020, 26, 1117-1126.

(54) Liu, H.; Liu, Y.; Li, J. Ionic liquids in surface electrochemistry. Phys. Chem. Chem. Phys. 2010, 12, 1685-1697.

(55) For a review see Zheng, A.; Liu, S.-B.; Deng, F. ${ }^{31}$ P NMR chemical shifts of phosphorus probes as reliable and practical acidity scales for solid and liquid catalysts. Chem. Rev. 2017, 117, 1247512531.

(56) Han, X.-X.; Du, H.; Hung, C.-T.; Liu, L.-L.; Wu, P.-H.; Ren, D.-H.; Huang, S.-J.; Liu, S.-B. Syntheses of novel halogenfree Brønsted-Lewis acidic ionic liquid catalysts and their applications for synthesis of methyl caprylate. Green Chem. 2015, 17, 499-508.

(57) Han, X.; Yan, W.; Hung, C.-T.; He, Y.; Wu, P.-H.; Liu, L.-L.; Huang, S.-J; Liu, S.-B. Transesterification of soybean oil to biodiesel by tin-based Brønsted-Lewis acidic ionic liquid catalysts. Korean J. Chem. Eng. 2016, 33, 2063-2072.

(58) Liu, Y.; Barath, E.; Shi, H.; Hu, J.; Camaioni, D. M.; Lercher, J. A. Solvent-determined mechanistic pathways in zeolite-H-BEAcatalysed phenol alkylation. Nat. Catal. 2018, 1, 141-147.

(59) Kauffman, J.; Bates, G. M.; Lenz, D. H.; Lohith, K.; Gyani, V. C.; Ofoegbu, O. E.; Woodbury, R.; Li, X.; Zhang, X. Phenol alkylation catalyst precursor and catalyst, method of forming catalyst, method of regenerating catalyst, and method of alkylating phenol. PCT Int. Appl WO 2018023015 A2 20180201, 2018.

(60) Lee, D. - H.; Kwon, K. - H.; Yi, C. S. Dehydrative C-H alkylation and alkenylation of phenols with alcohols: expedient synthesis for substituted phenols and benzofurans. J. Am. Chem. Soc. 2012, 134, 7325-7328.

(61) Tsuji, Y.; Toteva, M. M.; Garth, H. A.; Richard, J. P. Kinetic and thermodynamic barriers to carbon and oxygen alkylation of phenol and phenoxide ion by the 1-(4-methoxyphenyl)ethyl carbocation. J. Am. Chem. Soc. 2003, 125, 15455-15465.

(62) Denmark, S. E.; Weintraub, R. C.; Gould, N. D. Effects of charge separation, effective concentration, and aggregate formation on the phase transfer catalyzed alkylation of phenol. J. Am. Chem. Soc. 2012, 134, 13415-13429.

(63) Jin, H.; Ansari, M. B.; Park, S. - E. Chemoselective O- versus $\mathrm{C}$-alkylation of substituted phenols with cyclohexene over mesoporous ZSM-5. Appl. Catal., A 2014, 472, 184-190.

(64) Titze-Frech, K.; Ignatiev, N.; Uerdingen, M.; Schulz, P. S.; Wasserscheid, P. Highly selective aromatic alkylation of phenol and anisole by using recyclable bronsted acidic ionic liquid systems. Eur. J. Org. Chem. 2013, 30, 6961-6966.

(65) Blümel, M.; Crocker, R. D.; Harper, J. B.; Enders, D.; Nguyen, T. V. N-Heterocyclic olefins as efficient phase-transfer catalysts for base-promoted alkylation reactions. Chem. Commun. 2016, 52, $7958-7961$.

(66) Jeon, Y.; Sung, J.; Seo, C.; Lim, H.; Cheong, H.; Kang, M.; Moon, B.; Ouchi, Y.; Kim, D. Structures of ionic liquids with different anions studied by infrared vibration spectroscopy. J. Phys. Chem. B 2008, 112, 4735-4740.

(67) Rai, R.; Pandey, S. Evidence of water-in-ionic liquid microemulsion formation by nonionic surfactant Brij-35. Langmuir 2014, 30, 10156-10160.

(68) Imai, Y.; Abe, H.; Goto, T.; Yoshimura, Y.; Kushiyama, S.; Matsumoto, H. Orientational ordering of crystal domains in ionic liquid based mixtures. J. Phys. Chem. B 2008, 112, 9841-9846.

(69) Lloret, V.; Rivero-Crespo, M. A.; Vidal-Moya, J. A.; Wild, S.; Domenech-Carbo, A.; Heller, B. S. J.; Shin, S.; Steinruck, H.-P.; Maier, F.; Hauke, F.; Varela, M.; Hirsch, A.; Leyva-Perez, A.; Abellan, G. Few layer $2 \mathrm{D}$ pnictogens catalyze the alkylation of soft nucleophiles with esters. Nat. Commun. 2019, 10, 509-519.

(70) Kashin, A. S.; Ananikov, V. P. Monitoring chemical reactions in liquid media using electron microscopy. Nat. Rev. Chem. 2019, 3, 624-637.

(71) Nahrwold, M.; Weiss, C.; Bogner, T.; Mertink, F.; Conradi, J.; Sammet, B.; Palmisano, R.; Royo Gracia, S.; Preusse, T.; Sewald, N. Conjugates of modified cryptophycins and RGD-peptides enter target cells by endocytosis. J. Med. Chem. 2013, 56, 1853-1864.

(72) Barrette, W. C.; Johnson, H. W.; Sawyer, D. T. Voltammetric evaluation of the effective acidities (pK,') for Brønsted acids in aprotic solvents. Anal. Chem. 1984, 56, 1890-1898.

(73) Mendes, J. P.; Dunach, E.; Esperanca, J. M. S. S.; Medeiros, M. J.; Ribeiro, J. F.; Silva, M. M.; Olivero, S. Catalytic cyclization of 
propargyl bromoethers via electrogenerated nickel(I) tetramethylcyclam in ionic liquids: water effects. J. Electrochem. Soc. 2019, 166, G17-G24.

(74) Montiel, M. A.; Solla-Gullon, J.; Montiel, V.; Sanchez-Sanchez, C. M. Electrocatalytic studies on imidazolium based ionic liquids: defining experimental conditions. Phys. Chem. Chem. Phys. 2018, 20, 19160-19167. 